\title{
Rational designing of the internal water supply system in reconstructed residential buildings of mass standard series
}

\author{
Evgeny Orlov ${ }^{1 *}$ \\ ${ }^{1}$ Moscow State University of Civil Engineering (National Research University), Department of water \\ supply and wastewater treatment, 129337 Yaroslavskoe Shosse 26, Moscow, Russia
}

\begin{abstract}
The issues of water supply system reconstruction in mass series buildings are reviewed with consideration of water- and resource saving. Principal points for location of plumbing cells in apartments, arrangement of water devices and wastewater receivers, selection of pipelines for reconstructed water line are described. Comparative analysis of design variants of inner water line before and following reconstruction are given. It was found that applying the developed system design approaches the head losses in the inner water supply line will be significantly decreased as well as the water mains length will be decreased with material and installation saving. Based on the data the conclusions on necessity to review standard arrangement solutions of water supply systems in the reconstructed buildings were made. Recommendations on water loss reduction in the system by installation of special water saving fittings on water devices and touchless faucets.
\end{abstract}

Keywords: water supply, sewage, housing, plumbing

\section{Introduction}

Today due to the came on economic depression as well as unsatisfactory state of old residential buildings the urgent issues are reconstructions of old and slum dwellings which can include buildings of the first standard series built mainly in 50-60th of the last century. These are different types of five-storeyed block and brick buildings equipped with outdated utilities (water mains, sewage etc.) [1-3].

In the work [4] of S.N. Bulgakov and V.V. Leontiev the main issues concerning reconstructions of these buildings considering architectural and space-planning solutions are reviewed but utilities reconstructions issues are not investigated at all.

Economic feasibility of reconstruction of these buildings is proved in the monograph [4]. It should be also noted that it is relevant not only for big megacities but also for small and medium cities. It will enable to attract attention of new buyers in such small localities proposing dwellings reconstructed according to new requirements but with better ecology and cheaper prices per square meter, e.g. cities located at 30-40 km from the capital.

\footnotetext{
* Corresponding author: jeks-2003@yandex.ru
} 


\section{Peculiarities of sanitary equipment application}

A great number of five-storeyed buildings of 50-60th standard series (1-510, 1-511, 1-515 etc.) has one undeniable advantage - demolition of partition walls which are non-loadbearing. During building reconstruction, it enables to perform various replanning variants with area increase for reconstructed apartments improving quality of living for the future dwellers.

Concerning utilities of the inner water supply and water removal, they are in bad condition. The will be fully changed during building reconstruction. Problem of such old buildings is worsened by the fact that inner water supply calculation was performed for standard water devices (sink mixer, tap of toilet tank, single mixer above bath and wash stand). Nowadays a great number of dwellers install many devices for which the system was not accounted for (washers and dishwashers, jacuzzi tubs etc). Pressure drops were registered at consumers located on last floors (4-5th floors) which was caused by increased water consumption and use of a great number of water-retaining devices.

The disadvantages of reconstructed buildings are also very small areas of kitchens and utilities cores, availability of combined variants even in two-room apartments that is unacceptable in current terms. Thus upon reconstruction of such buildings it is required to considerably improve comfort of use of utilities e.g. water supply and sewage.

Considering the above problems, it is proposed to develop the reasonable methods for reconstruction of water supply and removal systems considering water and resource saving as well as energy efficiency as in the most cases during reconstruction these issues are almost not considered in the sphere of inner water supply and sewage.

Today the main problem arising during reconstruction of old and slum dwellings is that architectures engaged in reconstruction in most cases give attention to planning of dwelling premises in particular leaving in the second place the utilities of the building (water supply lines, sewage etc) and their position in the dwelling space more specifically. For example, utilities cores can be left with the same area that upon reconstruction so there is no question of full comfort of water line use.

During development, the sanitary utilities changed. Considering current requirements to comfort its area shall be increase as there shall be comfortably located also other water devices not designed previously in the system e.g. automatic washer or hydromassage bath. The Soviet concept that everything shall be minimized shall become history. The hygiene and sanitary level for the last 50-60 years has considerably increased which requires other attitude to this issue.

According to the author's opinion, the sanitary core size shall evolve in the same way as habitable rooms namely the area shall be increased not depending on a category (elite housing or economy class). Moreover, it is understood that the sanitary cores shall meet not only necessity in sanitary and hygienic procedures. It shall also provide for location of different fitness machines for relaxation in water and trainings also (e.g. bath-tubs for aquacycling - water cycle). Thus, the sanitary core can be a health compartment in an apartment of any consumer interested in maintenance of his/her physical state. This concept can be started to apply for elite housing smoothly introducing these ideas in buildings of business and economy classes.

The author proposes to design emergency chutes (dry hydroseals) for drain receipt in unforeseen leakage (it can be done in kitchen also) in all new sanitaryware cores (both in newly built buildings and in reconstructed premises). The existing leak protection systems work good in many case and cut off water supply in emergency in 3-5 seconds. But their installation is not regulated and required by any authorities which does not oblige habitants to install them. Flooding of neighbors living below can lead to deplorable consequences (equipment damage, wetting and excess dampening of building structures etc). It is feasible 
to install several receiving openings in the floor at once and rely on their emergency water receipt in case of leak.

It is more feasible to locate the utility core near the future kitchen. It enables to connect all water devices to one riser (cold water, sewage). Today there are different types of planning where kitchens are located at considerable distance from the utility core, which implies their connection to different risers. It results in excess expenditure of materials and makes the whole water supply and sewage system of the building more expensive. Also the consumer itself shall install several meters for the apartment. In most cases, it is related to absence of "resource saving designing" concept not only in architect thoughts but also in constructing engineer thoughts.

According to calculation, rules of the inner water line the pipeline length shall be minimum - head losses by length decreases and it is feasible to make as minimum turns in the system as possible - head losses to local resistance decreases. So it is required to proceed from the following. All water devices within an apartment shall be arranged on one wall avoiding pipeline bends (in-line device arrangement). As entry to the building is performed to the the part where the most devices are located so it will be rationally to located kitchens and utility cores on each floor as close to each other as possible. Thus, it is required to seek the minimum head losses, which in future may affect selection of pumping equipment. As an example two cases of arrangement solutions of utility cores and water supply systems before dwelling house reconstruction can be reviewed which will enable to draw the most objective conclusions.

Planning and routing of inner cold water supply system in a building before reconstruction (fig. 1, a) and basement plan (fig. 1, b) are given in fig. 1. It is seen that utility core sizes do not meet the comfort concept (they shall be increased in future, standard sizes are shown in the figure). The kitchen is located far from the utility core. The replanning variant considering up-to-date trends is shown in fig. 2. Previously not used area in single-room apartments is reconstructed in an additional room. Considering current trends, the kitchens are located near the utility cores removing a number of excessive risers in the system. All water feeders are arranged as close to each other as possible. Comparative data for two variants (before and after reconstruction) are given in table 1 .

It is seen from table 1 that about $53 \mathrm{~m}$ of pipelines were saved (installation and materials), head losses were considerably decreases in comparison with the variant before reconstruction as well as the more efficient pump was selected which in future will enable to reduce electric energy costs.

In addition, it is feasible to make some additional activities following the reconstruction. It is feasible to install special water saving fittings [5] on each mixer to reduce water losses in the reconstructed building. These devices are screwed on any standard mixer instead of default aerators. The water saving fitting is equipped with a metal bar. Its operating principle is as follows. First, the consumer sets the required temperature and head (turn a faucet or lever). Then it presses on a metal bar and water begins to be supplied from the device. To stop water flowing it is required to press again on the bar. Thus the exact amount of water is spent which is required (time for setting temperature and head is absent; the consumer consumes water at once). In addition, there are water saving fittings equipped with timers available in the market. The consumer sets himself/herself that the metal bar itself (mechanically) stops water supply after the set time (as a rule within 310 seconds). It is relatively easy to design a mixer, which will be initially equipped with such water saving fitting.

In addition, to save water it is feasible to use touchless faucets actuating upon hand putting to them as per SP 30.13330.2012 "Internal water supply lines and sewages of buildings". This new type of water devices is widely described in the following literature [6-14]. However, today it costs rather expensive and benefit from its use is if it is installed 
on a wash stand in the utility core. In the kitchen, such device will create certain discomfort when filling large volumes (kettles, pots etc). Thus water saving will be similar to water saving fittings described above.
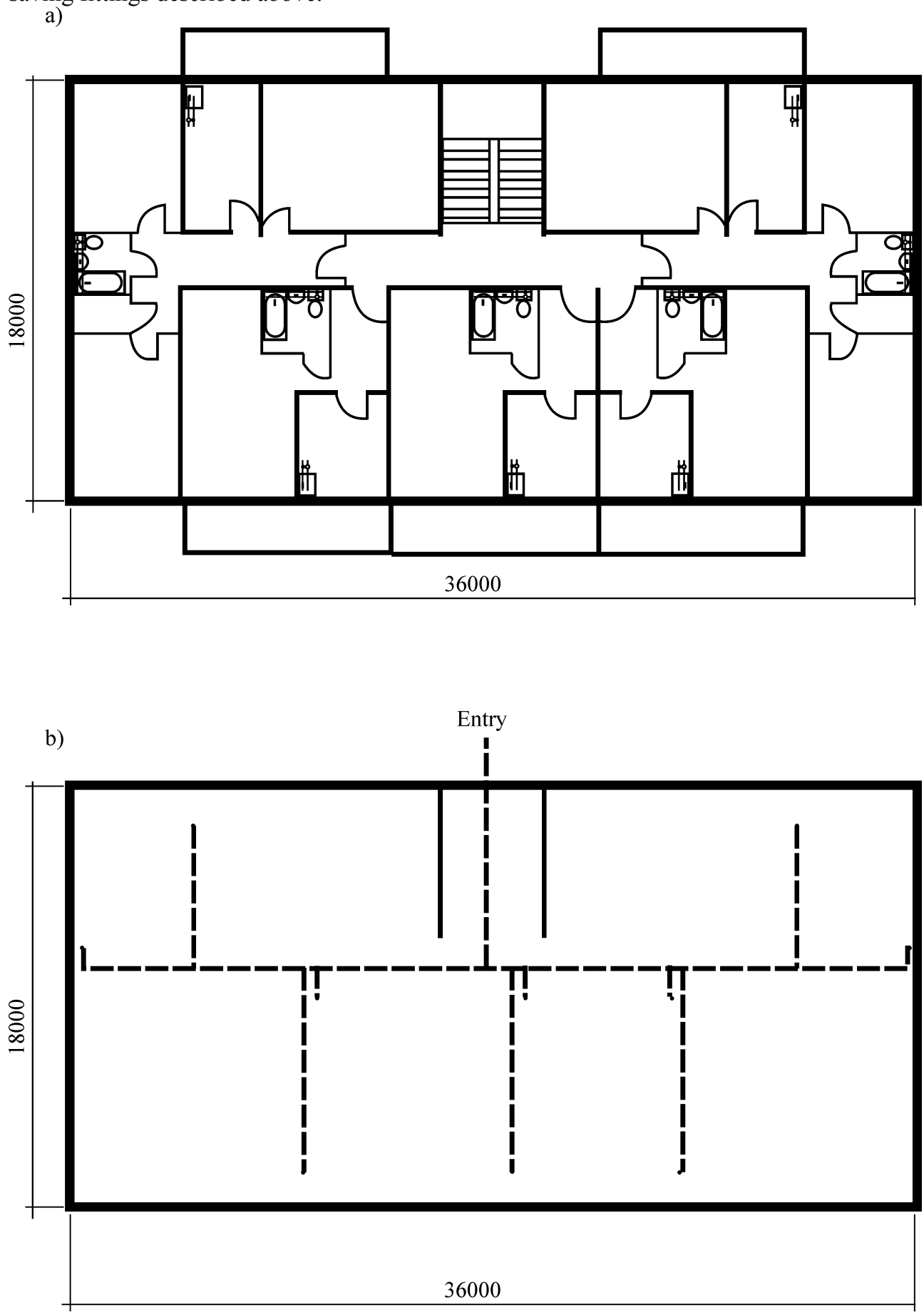

Fig. 1. Plan of standard floor of building (before reconstruction) with location of risers and sanitary ware (a) and basement plan (b) with location of pipe system and risers (dimensions in $\mathrm{mm}$ ) 

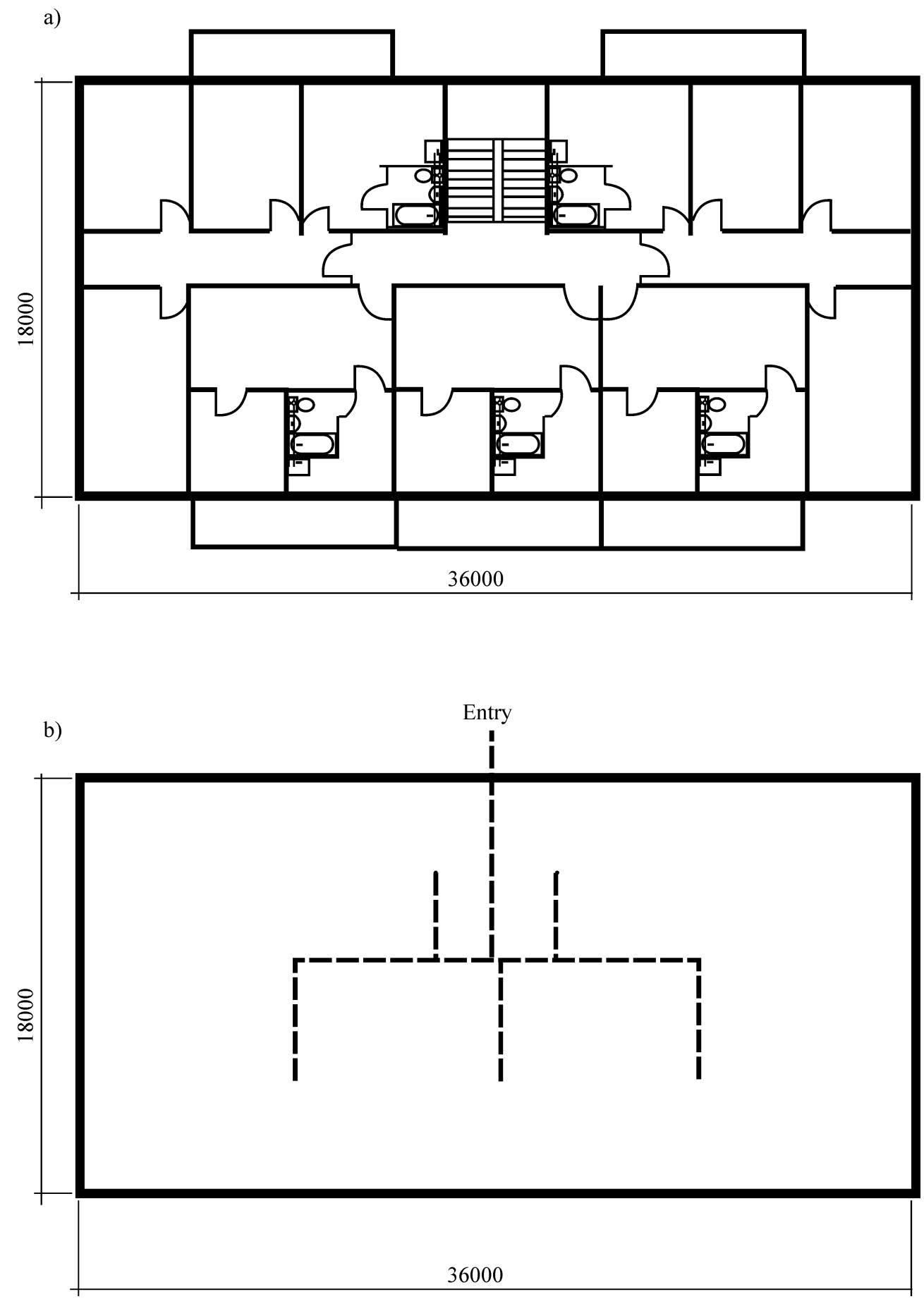

Fig. 2. Plan of standard floor of building (after reconstruction) with location of risers and sanitary ware (a) and basement plan (b) with location of pipe system and risers (dimensions in mm) 
Table 1. Comparative data for two design variants before and after reconstruction

\begin{tabular}{|c|c|c|c|}
\hline No. & Parameter & Before reconstruction & After reconstruction \\
\hline 1 & $\begin{array}{l}\text { Inner water supply } \\
\text { main length in } \\
\text { basement (without } \\
\text { entry and connections } \\
\text { to risers) }\end{array}$ & $35.2 \mathrm{~m}$ & $15.2 \mathrm{~m}$ \\
\hline 2 & $\begin{array}{l}\text { Length of the whole } \\
\text { water supply main in } \\
\text { basement }\end{array}$ & $88.7 \mathrm{~m}$ & $35.6 \mathrm{~m}$ \\
\hline 3 & Quantity of water risers & 10 nos. & 5 nos. \\
\hline 4 & $\begin{array}{l}\text { Quantity of served } \\
\text { water devices }\end{array}$ & 20 nos. & 20 nos. \\
\hline 5 & $\begin{array}{l}\text { Possibility to increase } \\
\text { usable area of utility } \\
\text { cores for creation of } \\
\text { health cells }\end{array}$ & No, standard area & $\begin{array}{l}\text { Yes, possibility to install } \\
\text { additional water devices }\end{array}$ \\
\hline 6 & Head losses by length & - & $\begin{array}{c}\text { Decrease of head losses by } \\
\text { length in } 2.5 \text { times }\end{array}$ \\
\hline 7 & $\begin{array}{l}\text { Head losses for local } \\
\text { resistances }\end{array}$ & - & $\begin{array}{l}\text { Decrease of head losses for } \\
\text { local resistances in } 2.5 \text { times }\end{array}$ \\
\hline 8 & $\begin{array}{l}\text { Selection of new } \\
\text { pumping equipment }\end{array}$ & - & $\begin{array}{l}\text { Selection of more saving } \\
\text { pumping equipment in } \\
\text { comparison with the variant } \\
\text { before reconstruction }\end{array}$ \\
\hline 9 & $\begin{array}{l}\text { Combined operation of } \\
\text { pump and elevated } \\
\text { water tank }\end{array}$ & No & $\begin{array}{l}\text { Pressure leveling in the } \\
\text { system in case of big water } \\
\text { draw-off in peak hours }\end{array}$ \\
\hline 10 & Inner sewage system & - & $\begin{array}{c}\text { Decrease of outlet number in } \\
\text { the system, pipeline number, } \\
\text { less time for equipment } \\
\text { installation }\end{array}$ \\
\hline
\end{tabular}

Upon building reconstruction of these standard series, the authors of the monograph [4] propose to add on several floors additionally increasing quantity of apartments in the building. In some cases, it is proposed to build one attic floor (added on on the top of the five-storeyed building) with planning which will not be same as the standard floor plan. However, in this issue it is proposed to use an attic floor (or its part) exactly for location of utilities e.g. elevated water tanks. It is particularly true for small localities where head is not sufficient for water supply to highly located consumers of water supply systems of top floors in particular hours, as a rule in the morning and in the evening upon large water draw-off.

\section{Conclusions}

Concerning pipeline selection for inner water supply systems then in accordance with SP 30.13330.2012 "Inner water supply lines and sewages of buildings. Revised edition of SNiP 2.04.01-95*" it is allowed to use the following pipe types: copper, bronze, brass, steel (with inner and external anticorrosion coating), polymeric pipes (polyethylene, polypropylene, polybutene etc.).

Use of copper pipes is topical now [15]. In foreign countries they are widely used due to their reliability (e.g. in high-rise construction) in comparison with steel pipelines. However, their high cost will not be acceptable for the customers who want to save money. 
Upon selection of polymer pipelines it is required to review such parameters of particular polymers as operating conditions, service life, transported liquid temperature, low roughness coefficient etc. Preferences shall be given to polymers with high life ratios to which polybutene pipes are related as an example [16-19]. They obtain well flexibility, high resistance to cracking, well chemical resistance, and high resistance to chafing. Such pipelines are easily welded and connected using press-type and threaded fittings.

Thus it should be summarized that application of the above recommendations will enable not only to design efficiently the inner water supply and sewage system of reconstructed building but also to obtain required water and resource saving effect in future having reduced costs for residential building operation.

\section{References}

1. Yu.P. Grigoriev, Ind. and Civ. Const., 11, 3 (2003).

2. V.A. Anikin, V.V. Guriev, Ind. and Civ. Const., 11, 10 (2003).

3. S.N. Bulgakov, I.V. Rybalko, Ind. and Civ. Const., 2, 45 (2006).

4. S.N. Bulgakov, V.V. Leontiev, Justified Reconstruction of Residential Buildings of the First Mass Series (ASV publishing house, Moscow, 2016).

5. E.V. Orlov, Scientific review. 3, 32 (2016).

6. V.N. Isaev, A.M. Smirnovskaya, World Equip. and Tech.. 6, 33 (2015).

7. V.N. Isaev, V.A. Nechitaeva, Wat. Suppl. and Sew., 4, 88 (2010).

8. V.N. Isaev, V.A. Chukhin, A.V. Gerasimenko, Sanitaryware. 3, 14 (2011).

9. V.N. Isaev, V.A. Chukhin, A.V. Gerasimenko, Sanitaryware. 6, 16 (2010).

10. E.V. Orlov, World Tech.. 10. 35 (2012).

11. A.V. Chistyakova, V.A. Chukhin, A.P. Andrianov, Wat. Purif.,Wat. Treat., Wat. Suppl., 1, 48 (2016).

12. A.G. Pervov, A.P. Andianov, D.V. Spitsov, V.V. Kondratiev, Wat. Purif., 1, 38 (2008).

13. E.V. Orlov, Ecol. of Urban. Terr., 1, 43 (2015).

14. V.N. Isaev, N.V. Aksenova, M.Ya. Balavas, Nat. and Eng. Sci., 5, 200 (2015).

15. V.A. Nechitaeva, A.V. Eremeev, World Equip. and Techn., 10, 26 (2015).

16. A.A. Otstavnov, Water Supply and Water Removal of Public Buildings (AVOKPRESS, Moscow, 2011).

17. A.A. Otstavnov, V.A. Kharkin, Sanitaryware, Heat., Air Cond., 1, 16 (2014).

18. N. Makisha, Procedia. Eng., 165, 1092-1097 (2016)

19. A. Kulakov, N. Makisha, MATEC Web of Conferences, 112, 10019 (2017) 